\title{
Association between screening and the thyroid cancer "epidemic" in South Korea: evidence from a nationwide study
}

\author{
Sohee Park, 1,2 Chang-Mo Oh, ${ }^{1}$ Hyunsoon Cho, ${ }^{1,3}$ Joo Young Lee, ${ }^{1,4}$ Kyu-Won Jung, ${ }^{1}$ Jae Kwan Jun,1,3 \\ Young-Joo Won, ${ }^{1,3}$ Hyun-Joo Kong, ${ }^{1}$ Kui Son Choi, ${ }^{1,3}$ You Jin Lee, ${ }^{5}$ Jin Soo Lee ${ }^{3,6}$
}

${ }^{1}$ National Cancer Control Institute, National Cancer Center, Goyang, Republic of Korea

${ }^{2}$ Department of Biostatistics, Yonsei University Graduate School of Public Health, Seoul, Republic of Korea

${ }^{3}$ Department of Cancer Control and Policy, Graduate School of Cancer Science and Policy,

National Cancer Center, Goyang, Republic of Korea

${ }^{4}$ Department of Preventive medicine, Yonsei University, College of Medicine, Seoul, Republic of Korea

${ }^{5}$ Center for Thyroid Cancer, National Cancer Center, Goyang, Republic of Korea

${ }^{6}$ National Cancer Center

Research Institute \& Hospital,

National Cancer Center, Goyang,

Republic of Korea

Correspondence to: I S Lee, National Cancer Center

Research Institute \& Hospital, National Cancer Center, 111.

Jungbalsan-ro, Ilsandong-gu,

Goyang, Gyeonggi-do 410-769,

Republic of Korea

jslee@ncc.re.kr

Additional material is published online only. To view please visit the journal online.

Cite this as: $B M J$ 2016;355:i5745 http://dx.doi.org/10.1136/bmj.i5745

Accepted: 21 October 2016

\author{
ABSTRACT \\ OBJECTIVE \\ To investigate whether screening for thyroid cancer led \\ to the current "epidemic" in South Korea.
}

\section{DESIGN}

Review of the medical records of nationally representative samples of patients with a diagnosis of thyroid cancer in 1999, 2005, and 2008.

\section{SETTING}

Sample cases were randomly selected from South Korea's nationwide cancer registry, using a systematic sampling method after stratification by region.

PARTICIPANTS

5796 patients with thyroid cancer were included (891 in 1999, 2355 in 2005, and 2550 in 2008).

\section{MAIN OUTCOME MEASURES}

The primary outcome was age standardised incidence of thyroid cancer and the changes in incidence between 1999 and 2008 according to the methods used to detect tumours (screen detection versus clinical detection versus unspecified).

\section{RESULTS}

Between 1999 and 2008, the incidence of thyroid cancer increased 6.4 -fold (95\% confidence interval 4.9-fold to 8.4-fold), from 6.4 (95\% confidence interval 6.2 to 6.6 ) per 100000 population to 40.7 (40.2 to 41.2) per 100000 population. Of the increase, $94.4 \%$ (34.4 per 100000 population) were for tumours less than $20 \mathrm{~mm}$, which were detected mainly by screening. $97.1 \%$ of the total increase was localised and regional tumours according to the Surveillance, Epidemiology, and End Results (SEER) summary stage. Where cases were clinically detected, $99.9 \%$ of the increased incidences (6.4 per 100000 population) over the same period were tumours less than $20 \mathrm{~mm}$.

\section{WHAT IS ALREADY KNOWN ON THIS TOPIC}

An increase in the incidence of thyroid cancer with little change in mortality has been observed in most countries

The increased incidence of thyroid cancer is mainly due to detection of small, well differentiated thyroid tumours

Overdiagnosis is considered to be the most plausible explanation; however, some remain unconvinced and have questioned this idea

\section{WHAT THIS STUDY ADDS}

This nationwide study found that the increase in thyroid cancer cases was due to an increase in the incidence of small tumours, which were detected mainly through screening

Screening for thyroid cancer can detect small tumours, as well as clinically indolent asymptomatic tumours with local extension and lymph node involvement

\section{CONCLUSION}

The current "epidemic" of thyroid cancer in South Korea is due to an increase in the detection of small tumours, most likely as a result of overdetection. Concerted efforts are needed at a national level to reduce unnecessary thyroid ultrasound examinations in the asymptomatic general population.

\section{Introduction}

In recent decades the incidence of thyroid cancer has increased steadily and consistently in many developed countries, ${ }^{1}$ most notably in South Korea, where the incidence increased by more than sevenfold, from 6.3 per 100000 population in 1999 to 47.5 per 100000 population in 2009. ${ }^{2}$ During that time, thyroid cancer became the most commonly diagnosed cancer in 2004 for women, and in 2009 for men and women combined. ${ }^{23}$ South Korea has the highest incidence of thyroid cancer in the world, ${ }^{4}$ which has raised public concern about the potential cause and also about the financial burden on the national healthcare system. The economic burden of thyroid cancer in South Korea increased about sevenfold, from $\$ 257 \mathrm{~m}$ (£207m; €232m) in 2000 to $\$ 1724 \mathrm{~m}$ in $2010,^{5}$ and outcomes could be similar for other countries. In the United States, for example, the incidence of thyroid cancer is expected to surpass that of colorectal cancer, to become the fourth most common malignancy by $2030 .{ }^{6}$ As such, the economic burden of well differentiated thyroid cancer in the United States is estimated to increase from more than $\$ 1.6 \mathrm{~b}$ in 2013 to more than $\$ 3.5 \mathrm{~b}$ in $2030 .^{7}$ Overdiagnosis is considered the most plausible explanation for this "epidemic" of thyroid cancer worldwide, especially in South Korea. ${ }^{89}$ Thyroid cancer related mortality has remained stable for several decades, ${ }^{12}$ despite there being no major improvement in treatment, as exemplified by the trend in thyroid cancer incidence and mortality in South Korea (fig 1). ${ }^{10}$ Further evidence shows a close correlation between the incidence rate of thyroid cancer and rates of screening for thyroid cancer by ultrasonography. In South Korea, previous studies reported a good correlation between the incidence of thyroid cancer in 2009 and screening rates in 2008 and $2009 . .^{811}$

Some investigators have, however, questioned the idea that overdiagnosis is the main cause of the current notable increase in cases of thyroid cancer. ${ }^{12-14}$ In a registry based cancer study, ${ }^{12}$ investigators observed that the incidence of both small and large thyroid tumours and the incidence of intrathyroidal and extrathyroidal cancers ${ }^{12}$ substantially increased from 1983 to 2006 in the United States. The researchers concluded that improved detection does not fully explain 


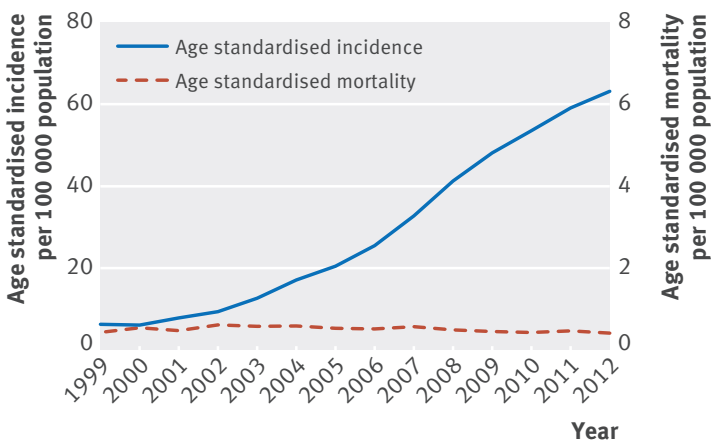

Fig 1 | Trends in incidence of and mortality from thyroid cancer in South Korea, 1999-2012. The age standardised rates use Segi's world standard population

the rising incidence of thyroid cancer. ${ }^{12}$ In Australia, an increase in thyroid cancer at early and advanced stages was observed across a range of sociodemographic groups. ${ }^{13}$ Furthermore, there were no substantial differences in tumour size, invasion, lymph node involvement, or distant metastasis between incidentally and non-incidentally diagnosed thyroid cancers in the United States. ${ }^{14}$ In this nationwide epidemiological study we investigated the recent increase in cases of thyroid cancer in relation to the methods used to detect tumours.

\section{Methods}

To investigate the reasons for the rapid increase in incidence of thyroid cancer in South Korea, in 2010 the Korea Central Cancer Registry conducted National Epidemiologic Survey of Thyroid cancer (NEST), which was designed to collect a representative sample of people with a diagnosis of thyroid cancer in 1999, 2005, or 2008. The study methods have been described previously, ${ }^{15}$ and the dataset is available on request (http:// kccrsurvey.cancer.go.kr/index.do).

We selected the study population from the registry database of all registered patients with thyroid cancer (3342 in 1999, 12659 in 2005, and 26890 in 2008). To do this, we used a two stage sampling method. Firstly, we used a probability-proportional-to-size method that was stratified by region in a given year to select 24 hospitals. Then we used a systematic sampling method to randomly select cases within each hospital. The number of cases diagnosed in 1999 and 2005 was smaller than in 2008, thus we applied different sampling proportions for each study year (33\% in 1999, 22\% in 2005, and $11 \%$ in 2008).

Using a predesigned data collection form, we collected basic personal variables from medical records. These included age and sex, and tumour related variables, such as tumour size, histological type, status of nodal and distant metastases, tumour stage (American Joint Committee on Cancer, cancer staging manual, sixth edition, ${ }^{16}$ Surveillance, Epidemiology, and End Results (SEER) summary staging manual ${ }^{17}$ ), and the way in which the tumour was detected. The SEER summary stage grouped thyroid cancers into three major categories-localised, regional, and distant.
The regional stage includes regional by direct extension only, only regional lymph nodes involved, and regional by both direct extension and regional lymph node involvement. ${ }^{17}$

In our study, we further categorised the regional stage into five subgroups according to lymph node involvement (yes or no) and the degree of extrathyroidal extension (none, minimal, or gross). ${ }^{1618}$ The way in which a tumour was detected was classified as screen detected (through cancer screening as recorded in medical records), clinically detected (by investigation of symptoms associated with thyroid disease, including thyroid cancer), and unspecified (or unknown). The histological subtypes of thyroid cancer were classified according to the International Classification of Diseases for Oncology, third edition ${ }^{19}$ as papillary carcinoma, medullary carcinoma, follicular carcinoma, anaplastic carcinoma, and others. ${ }^{20}$

Of 6846 patients selected at the first stage (1103 in 1999, 2785 in 2005, and 2958 in 2008), we excluded 1050 cases from the final analysis. These included 960 cases where the hospital refused to disclose medical records, and 90 cases with insufficient data in the medical records. Overall, 5796 patients were included in this study (891 in 1999, 2355 in 2005, and 2550 in 2008). To check whether the database of the National Epidemiologic Survey of Thyroid Cancer was comparable with the National Cancer Incidence Database, we compared the age and sex distribution (see supplementary table 1) and the estimated age standardised incidence of thyroid cancer (see supplementary table 2). The results from the two surveys were comparable for each given year.

\section{Statistical analysis}

We estimated the age standardised incidence rate of thyroid cancer for the three methods of tumours detection (screen versus clinical versus unspecified) by tumour size and SEER summary stage, for 1999, 2005, and 2008. To estimate the age standardised incidence of thyroid cancer, we calculated a weighted frequency for each five year age group for each study year, and then divided the weighted frequency by the corresponding mid-year population. The age standardised incidence rate was estimated using the weights for the proportions of corresponding five year age groups in the world standard (using Segi's standard population). ${ }^{21}$ The 95\% confidence interval was calculated per 100000 population (assuming that a Poisson distribution is appropriate). We calculated the absolute differences in the incidence of thyroid cancer according to the method of tumour detection by tumour size, SEER summary stage, and the American Joint Committee on Cancer stage between 1999 and 2008.

The baseline characteristics are presented as means with standard deviations or numbers (percentages), by year of detection. We used one way analysis of variance to compare the differences in continuous variables by year and $\chi^{2}$ test to compare the differences in categorical variables by year. $P$ values of less than 0.05 were considered statistically significant. All statistical 
analyses were performed using Stata 12.0 (StataCorp LP, TX) and SAS 9.3 (SAS Institute, Cary, NC).

\section{Patient involvement}

This study is a retrospective medical chart review of patients selected from the national cancer registry database. There was no direct contact with patients or individuals. No patients were involved in setting the research questions or the outcome measures, nor were

\begin{tabular}{|c|c|c|c|c|c|}
\hline \multirow[b]{2}{*}{ Variables } & \multirow[b]{2}{*}{ Total } & \multicolumn{3}{|l|}{ Year } & \multirow[b]{2}{*}{ Pvalue* } \\
\hline & & 1999 & 2005 & 2008 & \\
\hline Overall & 5796 & 891 & 2355 & 2550 & \\
\hline Mean (SD) age (years) & $46.9(12.4)$ & $46.0(14.3)$ & $47.3(12.5)$ & $46.8(11.6)$ & 0.03 \\
\hline Mean (SD) tumour size $(\mathrm{mm})$ & $13.3(11.7)$ & $21.5(15.9)$ & $13.6(11.1)$ & $10.5(9.0)$ & $<0.01$ \\
\hline Sex: & & & & & 0.01 \\
\hline Men & 898 (15.5) & $136(15.3)$ & 328 (13.9) & $434(17.0)$ & \\
\hline Women & $4898(84.5)$ & $755(84.7)$ & $2027(86.1)$ & $2116(83.0)$ & \\
\hline Methods of detectiont: & & & & & $<0.01$ \\
\hline Screening & $2655(45.8)$ & $134(15.0)$ & $1090(46.3)$ & $1431(56.1)$ & \\
\hline Clinical & $1784(30.8)$ & $447(50.2)$ & $773(32.8)$ & $564(22.1)$ & \\
\hline Unspecified & $1357(23.4)$ & $310(34.8)$ & $492(20.9)$ & $555(21.8)$ & \\
\hline Histological type‡: & & & & & $<0.01$ \\
\hline Follicular carcinoma & $173(3.0)$ & $62(7.0)$ & $66(2.8)$ & $45(1.8)$ & \\
\hline Papillary carcinoma & $5500(94.9)$ & $779(87.4)$ & $2243(95.2)$ & $2478(97.2)$ & \\
\hline Medullary carcinoma & $43(0.7)$ & $13(1.4)$ & $19(0.8)$ & $11(0.4)$ & \\
\hline Anaplastic carcinoma & $26(0.5)$ & $15(1.7)$ & $6(0.3)$ & $5(0.2)$ & \\
\hline Other & $54(0.9)$ & $22(2.5)$ & $21(0.9)$ & $11(0.4)$ & \\
\hline Regional lymph node involvement: & & & & & $<0.01$ \\
\hline No & 2466 (42.6) & $268(30.1)$ & $1012(43.0)$ & $1186(46.5)$ & \\
\hline Yes & $2047(35.3)$ & $319(35.8)$ & 799 (33.9) & $929(36.4)$ & \\
\hline Unknown & $1283(22.1)$ & 304 (34.1) & 544 (23.1) & $435(17.1)$ & \\
\hline Distant metastasis: & & & & & $<0.01$ \\
\hline No & $5380(92.8)$ & $774(86.9)$ & $2196(93.3)$ & $2410(94.5)$ & \\
\hline Yes & $34(0.6)$ & $15(1.7)$ & $14(0.6)$ & $5(0.2)$ & \\
\hline Unknown & $382(6.6)$ & $102(11.4)$ & $145(6.1)$ & $135(5.3)$ & \\
\hline Extrathyroidal extension: & & & & & $<0.01$ \\
\hline No & $2783(48.0)$ & $397(44.5)$ & $1194(50.7)$ & $1192(46.7)$ & \\
\hline Yes & $2593(44.7)$ & $357(40.1)$ & $993(42.2)$ & $1243(48.8)$ & \\
\hline Unknown & $420(7.3)$ & $137(15.4)$ & $168(7.1)$ & $115(4.5)$ & \\
\hline Focality: & & & & & $<0.01$ \\
\hline Unifocal & $3810(66.7)$ & $554(62.2)$ & $1553(65.9)$ & $1703(66.8)$ & \\
\hline Multifocal & $1697(29.3)$ & $234(26.3)$ & $689(29.3)$ & $774(30.3)$ & \\
\hline Unknown & $289(5.0)$ & $103(11.5)$ & $113(4.8)$ & $73(2.9)$ & \\
\hline $\begin{array}{l}\text { American Joint Committee on } \\
\text { Cancer stage: }\end{array}$ & & & & & $<0.01$ \\
\hline 1 & $3038(52.4)$ & $428(48.0)$ & 1249 (53.0) & $1361(53.3)$ & \\
\hline ॥ & $49(0.9)$ & $14(1.6)$ & $23(1.0)$ & $12(0.5)$ & \\
\hline III & $1036(17.9)$ & $97(10.9)$ & $373(15.8)$ & $566(22.2)$ & \\
\hline IV & $426(7.3)$ & $101(11.3)$ & $178(7.6)$ & $147(5.8)$ & \\
\hline Unknown & $1247(21.5)$ & $251(28.2)$ & $532(22.6)$ & $464(18.2)$ & \\
\hline SEER summary stage: & & & & & $<0.01$ \\
\hline Localised & $2125(36.6)$ & $302(33.9)$ & 919 (39.0) & $904(35.5)$ & \\
\hline Regional & $3176(54.8)$ & $425(47.7)$ & $1243(52.8)$ & $1508(59.1)$ & \\
\hline Distant & $126(2.2)$ & $48(5.4)$ & $45(1.9)$ & $33(1.3)$ & \\
\hline Unknown & $369(6.4)$ & $116(13.0)$ & $148(6.3)$ & $105(4.1)$ & \\
\hline
\end{tabular}

SEER=Surveillance, Epidemiology, and End Results.

${ }^{*}$ Calculated by one way analysis of variance for continuous variables and $\chi^{2}$ test for categorical variables. tClassified as screen detected (as recorded in medical records), clinically detected (through investigation of symptoms associated with thyroid disease, including thyroid cancer), and unspecified (or unknown). $\neq$ Classified based on International Agency for Research on Cancer (international classification of diseases for oncology, third edition). Extrathyroidal extension was determined on the basis of the American Joint Committee on Cancer (cancer staging manual, sixth edition). they involved in developing plans for recruitment, design, or implementation of the study. No patients were asked to advise on interpretation or writing up of results. The dataset for this study is available from http://kccrsurvey.cancer.go.kr/index.do on request.

\section{Results}

Table 1 shows the characteristics of the study population for each study year. Overall, $84.5 \%$ of the participants $(n=5796)$ were women, and the mean (SD) age was 46.9 (12.4) years. The most common histological type (94.9\%) was papillary carcinoma. The size of thyroid tumours steadily decreased from 1999 to 2008 . The proportion of screen detected tumours increased from $15.0 \%$ in 1999 to $56.1 \%$ in 2008 . The proportion of regional stage thyroid cancer increased from $47.7 \%$ in 1999 to $59.1 \%$ in 2008, while the proportion of localised SEER summary stage thyroid cancer remained stationary. The proportion of distant stage thyroid cancer decreased from 5.4\% in 1999 to $1.3 \%$ in 2008.

\section{Change in incidence of thyroid cancer over time by tumour size}

Table 2 and figure 2 (top panel) show the changes in the estimated incidence of thyroid cancer by tumour size for each method of tumour detection during 1999-2008. The incidence of screen detected tumours less than 10 mm increased steeply, from 0.27 (95\% confidence interval 0.22 to 0.31 ) per 100000 population in 1999 to 15.00 (14.70 to 15.29) per 100000 population in 2008, with an absolute difference of 14.73 . The incidence of clinically detected tumours less than $10 \mathrm{~mm}$ also showed a modest increase, from 0.49 per 100000 population in 1999 to 4.88 per 100000 population in 2008 (absolute difference 4.39). There was only a fractional increase in the incidence of screen detected tumours $30 \mathrm{~mm}$ or more and no significant increase in the incidence of such tumours detected clinically (absolute difference 0.00, $95 \%$ confidence interval -0.27 to 0.27 ). Overall, $94.4 \%$ of the total increase was attributed to the higher incidence of tumours less than $20 \mathrm{~mm}$. The increase in incidence of such tumours accounted for $99.9 \%$ of the increase in clinically detected thyroid cancer, compared with $93.7 \%$ of the increase in screen detected tumours.

About $60 \%$ of the absolute increase in thyroid cancer incidence between 1999 and 2008 occurred during 2005-08, especially for screen detected cases, where tumours were less than $20 \mathrm{~mm}$.

\section{Changes in incidence of thyroid cancer over time by SEER summary stage}

Table 2 and figure 2 (bottom panel) show the changes in estimated incidence of thyroid cancer according to the SEER summary stage. Overall, between 1999 and 2008 there was a 6.7-fold (95\% confidence interval 5.8-fold to 7.8-fold) increase in localised stage tumours and an 8.1-fold (7.2-fold to 9.2-fold) increase in regional stage tumours. This increase in regional stage tumours accounted for $61.6 \%$ of the total increase in thyroid cancer incidence between 1999 and 2008, and 35.5\% of the total increase was due to the increase in localised stage 


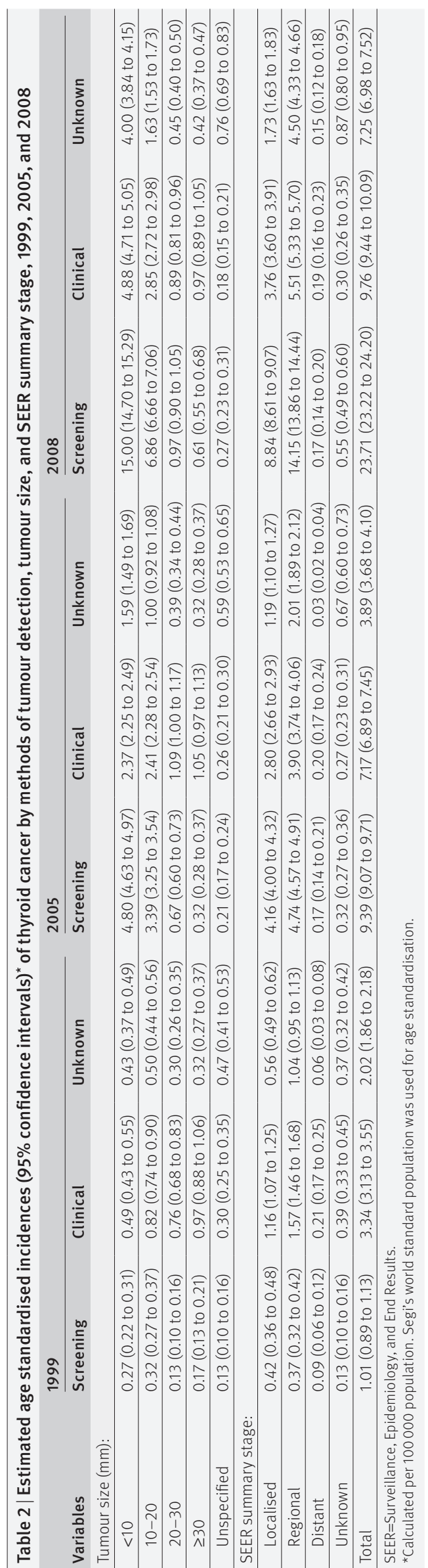

tumours. The incidence of distant stage thyroid cancer, however, increased little between 1999 and 2008.

A large increase was observed in the incidence of screen detected localised and regional stage cancers. The incidence of screen detected localised stage cancer increased by 8.4 -fold from 1999 to 2008 , and clinically detected localised stage thyroid cancer increased by 2.6-fold during the same period. The incidence of screen detected regional stage cancer increased by 38.2-fold, from 0.37 per 100000 population in 1999 to 14.15 per 100000 population in 2008 . The incidence of clinically detected regional stage cancer increased by 3.5-fold from 1999 to 2008. In contrast, there was only a fractional increase in the incidence of screen detected distant stage thyroid cancer, and there was no significant change in the incidence of clinically detected distant stage thyroid cancer (absolute difference -0.02 , 95\% confidence interval -0.14 to 0.10 ).

\section{Subgroup analysis of regional SEER summary stage tumours}

The regional SEER summary stage includes tumours with regional lymph node involvement and those with extrathyroidal extension. To better understand the true nature of the increase in the incidence of regional stage tumours over time, we further analysed the regional stage thyroid tumours by lymph node involvement (yes or no) and the degree of extrathyroidal extension (none, minimal, gross) according to the detection method by year (table 3 and fig 3). Most of the increase in incidence of regional stage thyroid cancer was due to lymph node involvement, about two thirds of which were with minimal extrathyroidal extension and one third without extrathyroidal extension. For the tumours without lymph node involvement, minimal extrathyroidal extension accounted for virtually all of the increase between 1999 and 2008. In terms of tumour detection method, there was a greater increase in the incidence of screen detected regional stage thyroid cancer than clinically detected regional stage tumours (absolute difference $13.8 v 3.9$ ), even for the tumours with lymph node involvement (absolute difference $8.3 v 2.2$ ).

\section{Changes in tumour size over time by method of tumour detection}

Overall, the median size of thyroid tumours decreased from $18 \mathrm{~mm}$ in 1999 to $8 \mathrm{~mm}$ in 2008 (see supplementary figure 1 and table 3 ). The size of screen detected tumours was notably smaller than that of clinically detected tumours $(\mathrm{P}<0.01)$; however, the magnitude of the decrease in median tumour size over time was greater for the clinically detected tumours (20 mm to $9 \mathrm{~mm}$ ) than for the screen detected tumours (14.5 $\mathrm{mm}$ to $8 \mathrm{~mm}$ ).

\section{Regional lymph node involvement by tumour size and method of tumour detection}

Supplementary table 4 shows the status of regional lymph node involvement by tumour size according to the methods of tumour detection. Overall, even tumours less than $10 \mathrm{~mm}$ were found to have regional lymph node involvement in more than one fifth of cases: $22.8 \%$ in 

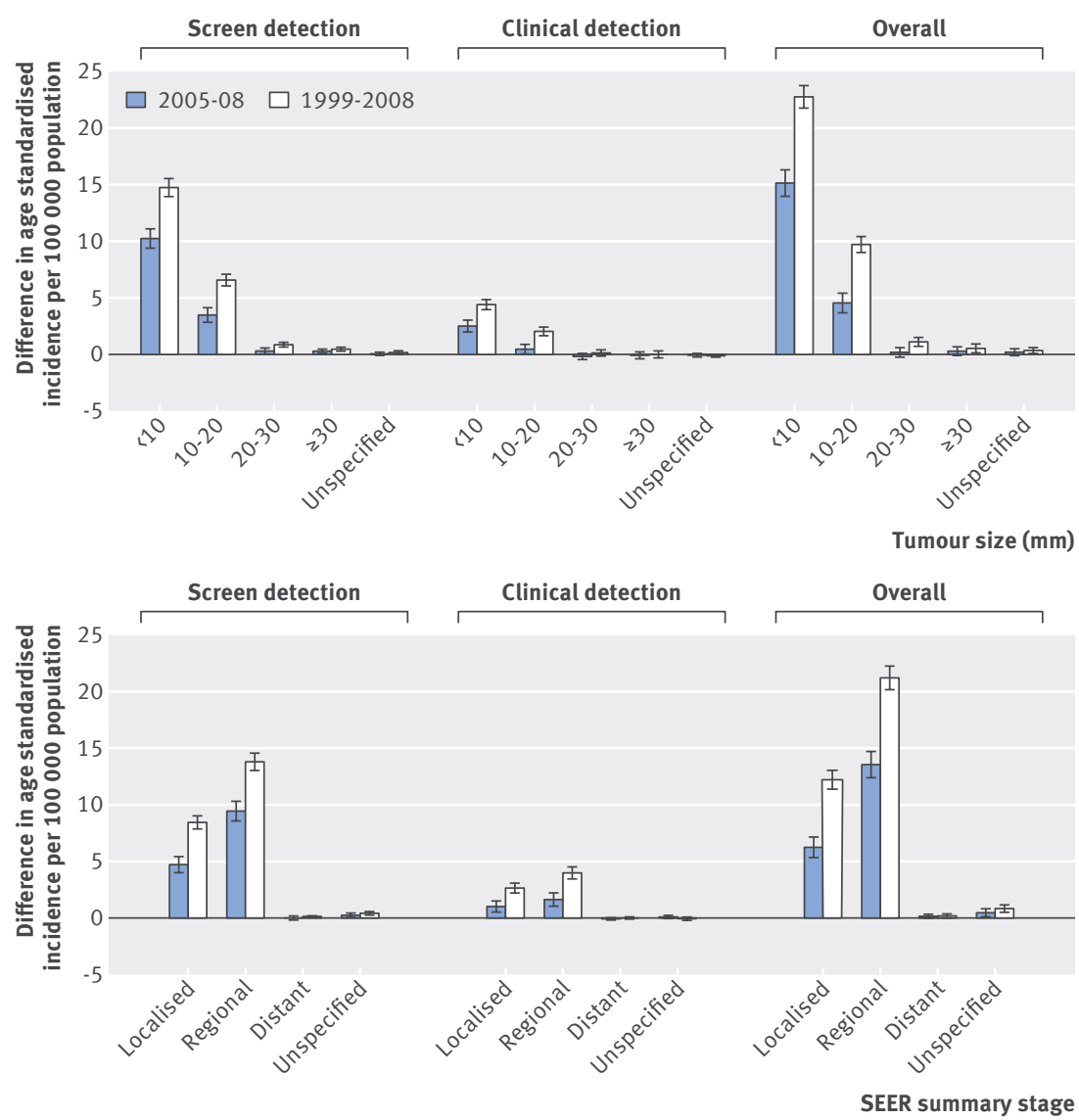

Fig 2 | Differences in age standardised incidence of thyroid cancer per 100000 population during 1999-2008 and 2005-2008 by tumour size (top panel) and by Surveillance, Epidemiology, and End Results (SEER) summary stage (bottom panel). Error bars represent $95 \%$ confidence intervals of differences in age standardised incidence

1999 and $28.4 \%$ in 2008. As the tumour size increased to 10-20 mm, 20-30 mm, and $30 \mathrm{~mm}$ or more, the proportion of cases with positive regional lymph node involvement increased accordingly. However, the method of tumour detection did not have any real impact on the status of regional lymph node involvement.

\section{Discussion}

Our study shows that most of the recent increases in the incidence of thyroid cancer in South Korea was due to greater detection of small $(<20 \mathrm{~mm})$ tumours, which accounted for $94.4 \%$ of the overall increase (34.4 per 100000 population) in the estimated incidence of thyroid cancer between 1999 and 2008. This increase is likely to be associated with the widespread practice of screening for thyroid cancer using ultrasonography, which started in the early 2000 s in South Korea. ${ }^{82}$ In our study, $97.1 \%$ of the increase in estimated incidence of thyroid cancer was due to greater detection of regional and localised stage tumours, for which five year relative rates of survival were $100.1 \%$ and $100.4 \%$, respectively, in South Korea. ${ }^{23}$ This finding of more than $100 \%$ relative survival rates means that people who have thyroid cancer and who are more likely to be screened for the cancer might be healthier and have a lower risk of dying than the general population, even in

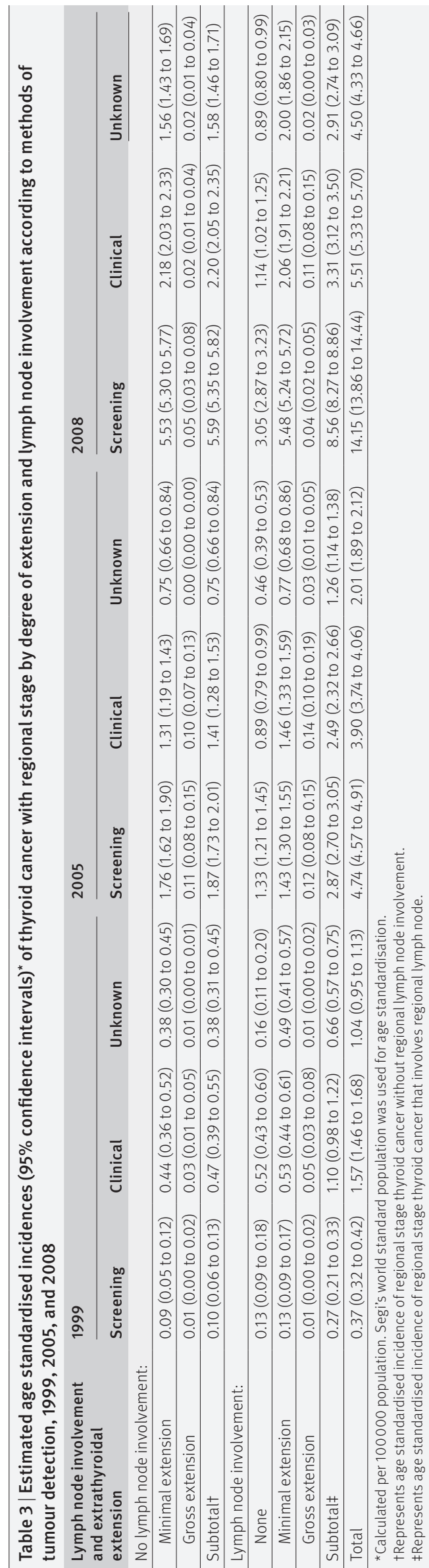




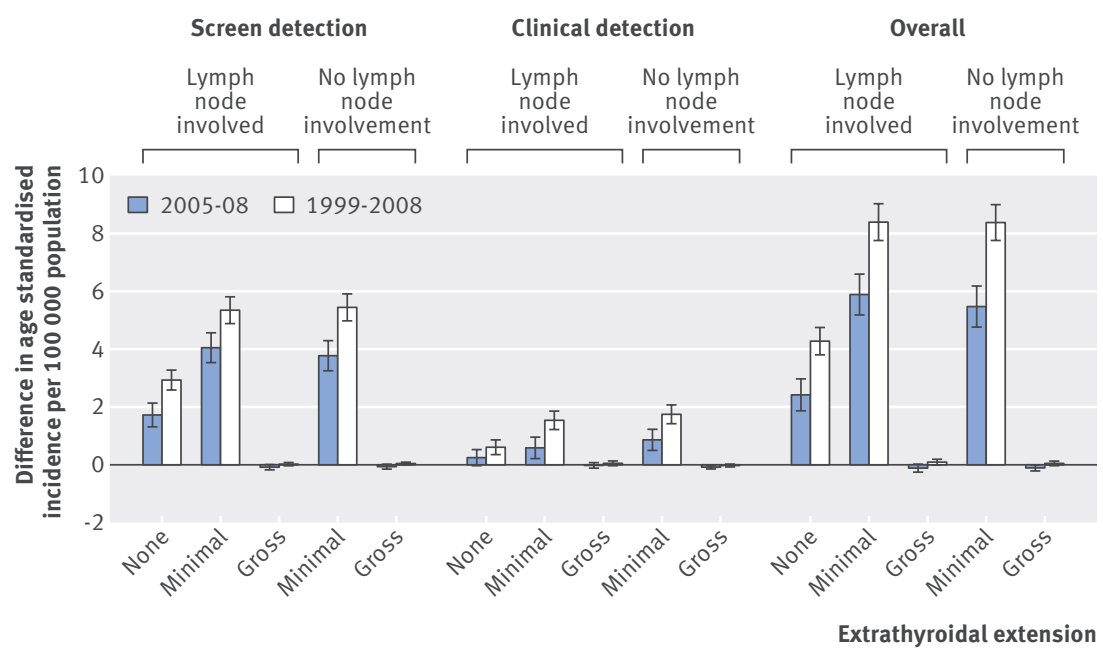

Fig 3 | Absolute change over time in incidence of regional stage thyroid cancer by lymph node involvement and degree of extrathyroidal extension according to detection methods. Error bars represent $95 \%$ confidence intervals of differences in age standardised incidence during study period thyroid cancer surgeries undertaken. ${ }^{25}$ Taken together with the accumulating data-which showed that mortality from thyroid cancer had remained stable for decades, despite the rapid increase in its incidence

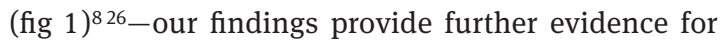
overdetection as a major contributor to the current thyroid cancer "epidemic" in South Korea.

\section{Strengths and weaknesses of this study}

Our study is meaningful as a nationwide survey that shows the change in incidence of thyroid cancer over time using a representative random sample of patients from cancer registry data. In addition, the study enables a better understanding of the mechanisms by which the incidences of thyroid cancer have recently increased, by analysing the data according to the methods of tumour detection and detailed pathological findings, including the size of tumour and nodal status.

However, this study has some limitations. Our data might have a misclassification bias for methods of tumour detection, which could cause either underestimation or overestimation of the incidence rate in specific subgroups. However, in our study, we used sample weights to calculate an unbiased estimate after adjusting for the non-response units. Indeed, the estimated incidence from NEST data was similar to the real incidence from cancer registry data (see supplementary tables 1 and 2). In addition, the estimated proportion of clinically detected cases from our findings in 2008 was similar to those from the Korea National Cancer Screening Survey study in $2009 .{ }^{27}$ Nevertheless, because of the relatively short follow-up, we could not secure the long term survival outcome data, which is the inherent limitation of this study of thyroid cancer.

\section{Comparison with other studies}

The reason for the increasing incidence of thyroid cancer in the past decade has been well debated and summarised in recent reviews. ${ }^{2829}$ Many experts suggested that the increase was a result of imaging tools being used more often for screening 89112630 ; others called for more epidemiological studies searching for yet unidentified causal factors. ${ }^{12-14}$

Some studies have shown that the incidences of small and large advanced stage thyroid cancer have increased. ${ }^{1231}$ Furthermore, a study of data from tertiary referral hospitals in the United States reported that the proportion of incidentally detected thyroid tumours not associated with symptoms did not increase, despite the increasing number of thyroid cancer cases overall. ${ }^{32}$ One study found that tumour size, invasion, lymph node involvement, and distant metastasis in patients with thyroid cancer detected incidentally were no different from those in patients with non-incidentally detected cancer. ${ }^{14}$ These findings, however, could be explained by the indolent nature of well differentiated thyroid tumours, which can grow to be large and can go undetected (even with lymph node involvement, as shown in this study, and extrathyroidal extension) until it is discovered incidentally through imaging investigations. ${ }^{33}$ 
To date, the only confirmed risk factor for thyroid cancer is exposure to ionising radiation. ${ }^{34}$ In South Korea, however, there were no discernible sources of additional radiation exposure other than the medical use of radioisotopes and diagnostic procedures, such as computed tomography. ${ }^{112735}$ Even if there were some increases in the incidence of thyroid cancer as a result of all those environmental factors, their contribution would be small. If the steep increase in incidence of thyroid cancer in South Korea is not a result of overdetection, it is hard to find a reasonable explanation for our findings of a 20.1-fold increase in small tumours $(<10$ $\mathrm{mm}$ ) and an 8.1-fold increase in regional stage tumours over the period 1999 to 2008.

Overdetection starts at the macro level, with how healthcare service is paid for at the system level, and extends down to the micro level, with how pathological specimens are processed now compared with how they were examined 30 years ago. ${ }^{2829}$ The increase in thyroid cancer incidence in South Korea coincides with the widespread use of ultrasound examination in local clinics, which followed reform of the nation's healthcare system in 2000. Many hospitals and clinicians encouraged routine health checks, which included the option of screening for thyroid cancer (for an additional fee, as this was not covered by national health insurance). A study of 10 major hospitals showed that the annual number of ultrasound examinations of the thyroid almost doubled between 2001 and 2004, and the annual number of examinations using ultrasound guided fine needle aspiration almost quadrupled during the same period. ${ }^{22}$ At the microscopic level, more careful examination of resected thyroid specimens could well have contributed to the increase in incidence of thyroid cancer. ${ }^{36}$

Generally, only nodules of more than $1 \mathrm{~cm}$ are recommended for further evaluation. ${ }^{24}$ If there is no increase in size or evidence of clinical progression of the tumour, some investigators recommend clinical observation for small papillary thyroid cancers, because they do not usually develop so aggressively. ${ }^{37-40}$ In South Korea, there was no discrete guideline for further evaluation of thyroid nodules until 2010, when the Korean Endocrine Society published a new guideline recommending the use of fine needle aspiration cytology for thyroid nodules of more than $5 \mathrm{~mm} .{ }^{41}$ However, because small papillary tumours are usually less aggressive there has been growing concern about the potential harm from side effects of unnecessary evaluation and subsequent treatment. Recently, a multidisciplinary expert committee, organised by the National Cancer Center Korea, developed a guideline for thyroid cancer screening. A consensus was that thyroid ultrasonography is not routinely recommended for healthy people. ${ }^{42}$

\section{Conclusion and policy implications}

Our study shows that the increase in the incidence of thyroid cancer in South Korea mainly resulted from overdetection, most likely as a result of widespread use of sensitive imaging tools (eg, ultrasound examination). Considering the increase in thyroid cancer incidence, ${ }^{12}$ the financial burden of using ultrasound to detect small tumours (and the often unnecessary subsequent surgery) is expected to rise rapidly. ${ }^{5-7}$ Concerted efforts are needed at national level to reduce unnecessary ultrasound examination of the thyroid in the asymptomatic general population, unless clinically indicated.

We thank the hospital staff and colleagues who collected patient information for the NEST study.

Contributors: SP and C-MO contributed equally to this study, and are joint first authors. All authors contributed to the data analysis and interpretation of the results, and reviewed and approved the final manuscript. JSL, the guarantor, had full access to all of the data in the study and takes responsibility for the integrity of the data and the accuracy of the data analysis. SP coordinated the study and wrote the manuscript. C-MO analysed the data and wrote the manuscript. SP, Y-JW, H-JK, and Y-JL collected and interpreted the data. HC, K-WJ, Y-JW, J-KJ, H-JK, K-SC, Y-JL, and JSL contributed to the discussion and reviewed and edited the manuscript.

Funding: This work was supported by a grant from the National Cancer Center (NCC-1310223 and NCC-1032020). The views expressed in this article are those of the authors and do not necessarily represent the views of the NCC, Goyang, Korea. The NEST survey was conducted with funding support from the NCC (NCC-1032020). The funders had no role in coordinating the study or writing the manuscript.

Competing interests: All authors have completed the ICMJE uniform disclosure form at www.icmje.org/coi_disclosure.pdf and declare: no support from any organisation for the submitted work; no financial relationships with any organisations that might have an interest in the submitted work in the previous three years; and no other relationships or activities that could appear to have influenced the submitted work.

Ethical approval: This research protocol was approved by the National Cancer Center institutional review board (NCC2015-0152).

Data sharing: The dataset for the NEST study is available on request (http://kccrsurvey.cancer.go.kr/index.do). Informed consent was not obtained, but the presented data are anonymised and the risk of identification is low.

Transparency: The lead author (JSL) affirms that the manuscript is an honest, accurate, and transparent account of the study being reported; that no important aspects of the study have been omitted; and that any discrepancies with the study as planned (and, if relevant, registered) have been explained.

This is an Open Access article distributed in accordance with the Creative Commons Attribution Non Commercial (CC BY-NC 3.0) license, which permits others to distribute, remix, adapt, build upon this work non-commercially, and license their derivative works on different terms, provided the original work is properly cited and the use is non-commercial. See: http://creativecommons.org/licenses/ by-nc/3.0/.

1 La Vecchia C, Malvezzi M, Bosetti C, et al. Thyroid cancer mortality and incidence: a global overview. Int J Cancer 2015;136:2187-95. doi:10.1002/ijc. 29251

2 Jung KW, Park S, Kong HJ, et al. Cancer statistics in Korea: incidence, mortality, survival, and prevalence in 2009. Cancer Res Treat 2012:44:11-24. doi:10.4143/crt.2012.44.1.11.

3 Won YJ, Sung J, Jung KW, et al. Nationwide cancer incidence in Korea, 2003-2005. Cancer Res Treat 2009;41:122-31. doi:10.4143/ crt.2009.41.3.122.

4 Ferlay J, Soerjomataram I, Ervik M, et al. GLOBOCAN 2012 v1.0, cancer incidence and mortality worldwide: IARC CancerBase No. 11.International Agency for Research on Cancer, 2013, http:// globocan.iarc.fr.

5 Lee KS, Chang HS, Lee SM, Park EC. Economic burden of cancer in Korea during 2000-2010. Cancer Res Treat 2015;47:387-98. doi:10.4143/crt.2014.001.

6 Rahib L, Smith BD, Aizenberg R, Rosenzweig AB, Fleshman JM, Matrisian LM. Projecting cancer incidence and deaths to 2030: the unexpected burden of thyroid, liver, and pancreas cancers in the United States. Cancer Res 2014;74:2913-21. doi:10.1158/0008-5472. CAN-14-0155.

7 Lubitz CC, Kong CY, McMahon PM, et al. Annual financial impact of well-differentiated thyroid cancer care in the United States. Cancer 2014:120:1345-52. doi:10.1002/cncr.28562.

8 Ahn HS, Kim HJ, Welch HG. Korea's thyroid-cancer "epidemic"screening and overdiagnosis. N Engl I Med 2014;371:1765-7. doi:10.1056/NEJMp1409841. 
9 Welch HG, Black WC. Overdiagnosis in cancer. I Natl Cancer Inst 2010;102:605-13. doi:10.1093/inci/djq099.

10 Jung KW, Won YJ, Kong HJ, et al. Cancer statistics in Korea: incidence, mortality, survival, and prevalence in 2012. Cancer Res Treat 2015;47:127-41. doi:10.4143/crt.2015.060.

11 Oh CM, Jung KW, Won YJ, Shin A, Kong HJ, Lee JS. Age-period-cohort analysis of thyroid cancer incidence in Korea. Cancer Res Treat 2015;47:362-9. doi:10.4143/crt.2014.110.

12 Morris LG, Myssiorek D. Improved detection does not fully explain the rising incidence of well-differentiated thyroid cancer: a population-based analysis. Am J Surg 2010;200:454-61. doi:10.1016/j.amjsurg.2009.11.008.

13 Pandeya N, McLeod DS, Balasubramaniam K, et al. Increasing thyroid cancer incidence in Queensland, Australia 1982-2008-true increase or overdiagnosis?Clin Endocrinol (Oxf) 2015. doi:10.1111/cen.12724.

14 Yoo F, Chaikhoutdinov I, Mitzner R, Liao J, Goldenberg D. Characteristics of incidentally discovered thyroid cancer. JAMA Otolaryngol Head Neck Surg 2013:139:1181-6 doi:10.1001/jamaoto.2013.5050.

15 Oh CM, Park S, Lee JY, et al. Increased prevalence of chronic lymphocytic thyroiditis in Korean patients with papillary thyroid cancer. PLoS One 2014:9:e99054. doi:10.1371/journal.pone.0099054.

16 Greene FL, Page DL, Fleming ID, et al, eds. AJCC cancer staging manual. 6th ed. Springer-Verlag Press, 2002doi:10.1007/978-1-4757-3656-4.

17 Young JLJr, , Roffers SD, Ries LAG, et al. SEER summary staging manual 2000: Codes and coding instructions. NIH Pub. No. 01-4969. National Cancer Institute, 2001

18 Hay ID, Johnson TR, Thompson GB, Sebo TJ, Reinalda MS. Minimal extrathyroid extension in papillary thyroid carcinoma does not result in increased rates of either cause-specific mortality or postoperative tumor recurrence. Surgery 2016;159:11-21. doi:10.1016/j.surg.2015.05.046.

19 Fritz A, Percy C, Jack A, et al, eds. International Classification of Diseases for Oncology.3rd ed. World Health Organization, 2000.

20 Forman D, Bray F, Brewster DH, et al, eds. (electronic version). Vol XIARC, 2013. (Cancer incidence in five continents.).

21 Segi M. Cancer mortality for selected sites in 24 countries (1950-57). Department of Public Health, Tohoku University of Medicine, 1960.

22 Kim SH, Jung SL, Moon WJ, et al. The prevalence of thyroid nodules and thyroid cancers in the Koreans: The nationwide data analysis of thyroid ultrasonography in 2004. J Korean Thyroid Assoc 2009;2:33-7.

23 Jung KW, Won YJ, Kong HJ, Oh CM, Shin A, Lee JS. Survival of Korean adult cancer patients by stage at diagnosis, 2006-2010: national cancer registry study. Cancer Res Treat 2013;45:162-71. doi:10.4143/ crt.2013.45.3.162

24 Haugen BR, Alexander EK, Bible KC, et al. 2015 American Thyroid Association management guidelines for adult patients with thyroid nodules and differentiated thyroid cancer: the American Thyroid Association guidelines task force on thyroid nodules and differentiated thyroid cancer. Thyroid 2016;26:1-133. doi:10.1089/thy.2015.0020.

25 Ahn HS, Welch HG. South Korea's thyroid-cancer "epidemic"-turning the tide. N Engl I Med 2015;373:2389-90. doi:10.1056/NEJMc1507622.

26 Davies L, Welch HG. Current thyroid cancer trends in the United States. JAMA Otolaryngol Head Neck Surg 2014:140:317-22. doi:10.1001/ jamaoto.2014.1.

27 Han MA, Choi KS, Lee HY, Kim Y, Jun JK, Park EC. Current status of thyroid cancer screening in Korea: results from a nationwide interview survey. Asian Pac / Cancer Prev 2011:12:1657-63.
28 Davies L, Morris LG, Haymart M, et al. AACE Endocrine Surgery Scientific Committee. American Association of Clinical Endocrinologists and American College of Endocrinology disease state clinical review: the increasing incidence of thyroid cancer. Endocr Pract 2015;21:686-96. doi:10.4158/EP14466.DSCR.

29 Pellegriti G, Frasca F, Regalbuto C, Squatrito S, Vigneri R. Worldwide increasing incidence of thyroid cancer: update on epidemiology and risk factors. J Cancer Epidemiol 2013;2013:965212. doi:10.1155/2013/965212.

30 Brito JP, Morris JC, Montori VM. Thyroid cancer: zealous imaging has increased detection and treatment of low risk tumours. $B M$ 2013;347:f4706. doi:10.1136/bmj.f4706.

31 Chen AY, Jemal A, Ward EM. Increasing incidence of differentiated thyroid cancer in the United States, 1988-2005. Cancer 2009;115. 3801-7. doi:10.1002/cncr.24416.

32 Bahl M, Sosa JA, Nelson RC, Esclamado RM, Choudhury KR, Hoang JK. Trends in incidentally identified thyroid cancers over a decade: a retrospective analysis of 2,090 surgical patients. World / Surg 2014:38:1312-7. doi:10.1007/s00268-013-2407-9.

33 Malone MK, Zagzag J, Ogilvie JB, Patel KN, Heller KS. Thyroid cancers detected by imaging are not necessarily small or early stage. Thyroid 2014;24:314-8. doi:10.1089/thy.2012.0651.

34 Veiga LH, Holmberg E, Anderson H, et al. Thyroid cancer after childhood exposure to external radiation: an updated pooled analysis of 12 studies. Radiat Res 2016;185:473-84. doi:10.1667/RR14213.1.

35 Kweon SS, Shin MH, Chung IJ, Kim YJ, Choi JS. Thyroid cancer is the most common cancer in women, based on the data from populationbased cancer registries, South Korea. Jpn J Clin Oncol 2013;43:103946. doi:10.1093/jjco/hyt102.

36 Grodski S, Brown T, Sidhu S, et al. Increasing incidence of thyroid cancer is due to increased pathologic detection. Surgery 2008;144:1038-43, discussion 1043. doi:10.1016/i.surg.2008.08.023.

37 Ito Y, Uruno T, Nakano K, et al. An observation trial without surgical treatment in patients with papillary microcarcinoma of the thyroid. Thyroid 2003:13:381-7. doi:10.1089/105072503321669875.

38 Castro MR, Morris JC, Ryder M, Brito JP, Hay ID. Most patients with a small papillary thyroid carcinoma enjoy an excellent prognosis and may be managed with minimally invasive therapy or active surveillance. Cancer 2015;121:3364-5. doi:10.1002/cncr.29468.

39 Miyauchi A. Clinical trials of active surveillance of papillary microcarcinoma of the thyroid. World J Surg 2016;40:516-22. doi:10.1007/s00268-015-3392-y.

40 Oda H, Miyauchi A, Ito Y, et al. Incidences of unfavorable events in the management of low-risk papillary microcarcinoma of the thyroid by active surveillance versus immediate surgery. Thyroid 2016;26:150-5. doi:10.1089/thy.2015.0313.

41 Yi KH, Park YJ, Koong SS, et al. Revised Korean thyroid association management guidelines for patients with thyroid nodules and thyroid cancer. Endocrinol Metab (Seoul) 2010;25:270-97doi:10.3803/ EnM.2010.25.4.270.

42 Yi KH, Kim SY, Kim DH, et al. The Korean guideline for thyroid cancer screening. J Korean Med Assoc 2015;58:302-12doi:10.5124/ jkma.2015.58.4.302

Supplementary information: supplementary figure 1 and tables 1-4 